\title{
DISC DEGENERATION: CURRENT SURGICAL OPTIONS
}

\author{
C. Schizas ${ }^{1 *}$, G. Kulik ${ }^{1}$, and V. Kosmopoulos ${ }^{2}$ \\ 'Département de l'Appareil Locomoteur, Site Hôpital Orthopédique, Centre Hospitalier Universitaire Vaudois and \\ The University of Lausanne, Lausanne, Switzerland \\ ${ }^{2}$ Bone and Joint Research Center, Department of Orthopaedic Surgery, University of North Texas Health Science \\ Center, Fort Worth, TX, USA
}

\begin{abstract}
Chronic low back pain attributed to lumbar disc degeneration poses a serious challenge to physicians. Surgery may be indicated in selected cases following failure of appropriate conservative treatment. For decades, the only surgical option has been spinal fusion, but its results have been inconsistent. Some prospective trials show superiority over usual conservative measures while others fail to demonstrate its advantages. In an effort to improve results of fusion and to decrease the incidence of adjacent segment degeneration, total disc replacement techniques have been introduced and studied extensively. Short-term results have shown superiority over some fusion techniques. Mid-term results however tend to show that this approach yields results equivalent to those of spinal fusion. Nucleus replacement has gained some popularity initially, but evidence on its efficacy is scarce. Dynamic stabilisation, a technique involving less rigid implants than in spinal fusion and performed without the need for bone grafting, represents another surgical option. Evidence again is lacking on its superiority over other surgical strategies and conservative measures. Insertion of interspinous devices posteriorly, aiming at redistributing loads and relieving pain, has been used as an adjunct to disc removal surgery for disc herniation. To date however, there is no clear evidence on their efficacy. Minimally invasive intradiscal thermocoagulation techniques have also been tried, but evidence of their effectiveness is questioned. Surgery using novel biological solutions may be the future of discogenic pain treatment. Collaboration between clinicians and basic scientists in this multidisciplinary field will undoubtedly shape the future of treating symptomatic disc degeneration.
\end{abstract}

Keywords: Degenerative disc disease, lumbar spine, surgery, low back pain, spinal fusion, total disc arthroplasty, dynamic stabilisation, interspinous devices, nucleous replacement.

\footnotetext{
*Address for correspondence:

C. Schizas

Département de l'Appareil Locomoteur,

Site Hôpital Orthopédique,

Centre Hospitalier Universitaire Vaudois and

The University of Lausanne,

Avenue Pierre-Decker 4

CH-1011 Lausanne, Switzerland

E-mail: cschizas@hotmail.com
}

\section{Introduction}

About $70-85 \%$ of adults suffer from low back pain at some point during their life, implicating low back pain as one of the primary reasons for physician office visits (Hart et al., 1995; Andersson, 1999; Deyo and Weinstein, 2001; Fritzell et al., 2001). Studies suggest low back pain to be multi-factorial, initiating for example from structures including spinal muscles and ligaments, spinal nerve roots, and the intervertebral disc (IVD) (Deyo and Weinstein, 2001; Fritzell et al., 2001). The IVD is located between two adjacent vertebrae in the spine and is designed to sustain, distribute, and transmit pressure between vertebrae and allow for some joint mobility while resisting excessive motion. The IVD is composed of the central nucleus pulposus which has higher water and proteoglycan content and lower collagen content when compared to the surrounding torus-like outer annulus fibrosus (Eyre, 1979; Cassinelli et al., 2001). The proportion of these constituents within the nucleus and annulus vary with aging, degeneration, and post injury, and have a large influence on the resulting biomechanical behaviour of the tissue (Skaggs et al., 1994; Acaroglu et al., 1995; Ferguson and Steffen, 2003).

Some degree of disc degeneration can be observed in most adults (Miller et al., 1976). Lumbar disc degeneration may occur due to a number of factors. Implicated, for example, are chemical, mechanical, and/or genetic factors (Hadjipavlou et al., 1999; Cassinelli et al., 2001; Martin et al., 2002). Biochemically, disc degeneration can be observed as a loss in proteoglycans resulting in tissue dehydration, and affecting transport of nutrients and cellular waste products (Ohshima et al., 1995; Cassinelli et al., 2001). Mechanically, disc degeneration alters the material properties of the IVD, leading to an unfavourable distribution and transmission of stresses to adjacent spinal structures (e.g., facet joints) (Butler et al., 1976). Genetically, several mechanisms have been implicated in disc degeneration, including Taq I and Fok I of the vitamin D receptor gene (Videman et al., 1998; Kawaguchi et al., 2002; Cheung et al., 2006; Hadjipavlou et al., 2008). However, since these aforementioned factors (i.e., chemical, mechanical, and genetic) are interrelated, which initiates disc degeneration is still debatable (Hadjipavlou et al., 2008).

Clinically, biochemical disc degeneration can be accurately identified by a low signal intensity in a lumbar IVD using T2-weighted magnetic resonance imaging (MRI) (Tertti et al., 1991). However, early and frequent use of imaging is discouraged as this may lead to overdiagnosis, patient anxiety and unnecessary treatment and 
expense (Deyo and Weinstein, 2001). IVD degeneration is a common observation in asymptomatic patients. Studies have shown that IVD degeneration of some sort can be observed on lumbar MRI scans in 34\% of subjects between 20-39 years of age and in approximately $93 \%$ of adults between 60-80 years of age without the concurrence of back pain (Boden et al., 1990). It is therefore important to realise that disc degeneration is symptomless in the majority of cases and this may only lead to symptoms of clinical significance in a small number of cases.

Disc degeneration in itself can lead not only to back pain, but also leg pain (sciatica) secondary to disc herniation, spinal canal stenosis, and spinal deformities. The vast majority of low back pain patients will improve within the first three months and usually conservative treatment is recommended in the initial phase. Examples of conservative treatment options include: physical therapy; medication; exercise; manipulation; attendance of so called "back schools"; as well as a multidisciplinary approach evaluating the social, psychological, and occupational parameters. Such non-surgical options should be exhausted before spine surgery is considered.

\section{Surgical Treatment Options}

\section{Spinal fusion/spinal arthrodesis}

Spinal fusion has been practiced since the beginning of the $20^{\text {th }}$ century and was mainly used for spinal deformities and infections in particular in spinal tuberculosis cases (Pott's disease) with vertebral collapse and kyphosis.(Albee, 1911; Hibbs, 1911). Today, fusion is the most commonly performed spinal operation. It is widely employed for trauma, tumours, infections, deformities, and IVD disease. Spinal fusion involves the use of bone tissue, classically achieved using an autograft (e.g., iliac crest or lamina), to bridge two or more vertebrae. Given the morbidity of iliac crest harvesting, alternatives have been developed consisting of the use of allografts, demineralised bone matrix (DBM), ceramics, and more recently bone morphogenetic proteins. The objective is to stabilise the motion segment, and eliminate the progression of disc degeneration and relative pathological motion between vertebrae, with the hypothesis that this change in mechanical environment relieves pain (Hanley and David, 1999; Kishen and Diwan, 2010).

Currently, indications for spinal fusion include: failure of aggressive conservative treatment, prolonged chronic pain, disability for greater than one year, and advanced disc degeneration as identified on MRI limited to one or two disc levels (Sidhu and Herkowitz, 1997; Andersson and Shen, 2004). However, due to the multifactorial nature of low back pain and the limited and inconsistent success of spinal fusion, indications for surgery vary between countries and surgeons (Fritzell et al., 2001).

Various techniques exist to achieve lumbar spinal fusion. Using a posterior approach, techniques include: posterolateral fusion; posterior lumbar interbody fusion (PLIF); and transforaminal lumbar interbody fusion (TLIF). More complex techniques use an anterior approach (e.g.; anterior lumbar interbody fusion - ALIF), or a combined approach, known as anteroposterior fusion or as 360 degrees fusion. Fusion surgery may be performed with or without additional instrumentation but patient outcomes are still controversial (Sidhu and Herkowitz, 1997; Bono and Lee, 2004; Gibson and Waddell, 2005; Soegaard and Christensen, 2006). Historically, non-union (pseudoarthrosis) was a common problem with uninstrumented spinal fusion. Implants have been progressively introduced (e.g., wires, hooks, pedicle screws) to help stabilise the spine for fusion. Nowadays, pedicle screws are wildly employed in posterior approaches, since they help stabilise the spine in multiple planes and have been shown to decrease the rate of nonunion (Grubb and Lipscomb, 1992; Zdeblick, 1993; Wood et al., 1995; Sidhu and Herkowitz, 1997).

Posterolateral fusion consists of applying bone graft, usually harvested at the iliac crest, between the transverse processes of the lumbar vertebrae. Posterior lumbar interbody fusion, PLIF, popularised by Cloward (Cloward, 1953), has been the most popular posterior technique. The technique consists of inserting a usually hollow implant (cage), filled with bone graft or bone substitutes, within the allowable disc space clearance with the addition of pedicle instrumentation to stabilise the segment (Fig. 1A,B). A disadvantage of this technique, as compared to anterior techniques, is that it can produce more neurological complications, bleeding, and subsequent scar formation within the spinal canal (Krishna et al., 2008). A variation of this technique is the transforaminal lumbar interbody fusion method, TLIF. This technique has been popularised by Harms and Rolinger and offers the advantage of avoiding exposing the spinal canal since the cage is introduced unilaterally through the intervertebral foramen (Harms and Rolinger, 1982). Recently, advances in instrumentation and the design of special implants have allowed fusion procedures, such as TLIF, to be performed through smaller skin incisions with the consequent benefit of decreased blood loss (Schizas et al., 2009).

Anterior fusion techniques in the lumbar spine have been used since the early thirties. ALIF requires removal of a large portion of the annulus fibrosus and the anterior longitudinal ligament, which in turn allows for more complete discectomy of the IVD (the possible source of pain) as compared to PLIF (Hanley and David, 1999; Tsantrizos et al., 2000; Hannani and Delamarter, 2004). Furthermore, as compared to posterolateral fusion, ALIF is advantageous in that it restores disc height, reduces operating time and generally favours load transmission due to the location of the graft, (Tsantrizos et al., 2000; Hannani and Delamarter, 2004) (Fig. 2). Nevertheless, there are some drawbacks. Concerns include more serious complications such as vascular lesions, and in the lumbosacral junction, injury to the presacral plexus can result rarely in retrograde ejaculation and sterility in male patients (Baker et al., 1993; Jeanneret et al., 1994; Hanley and David, 1999).

Even though spinal fusion is commonly performed, its role in treating discogenic low back pain has been controversial with conflicting results (Gibson et al., 1999; 

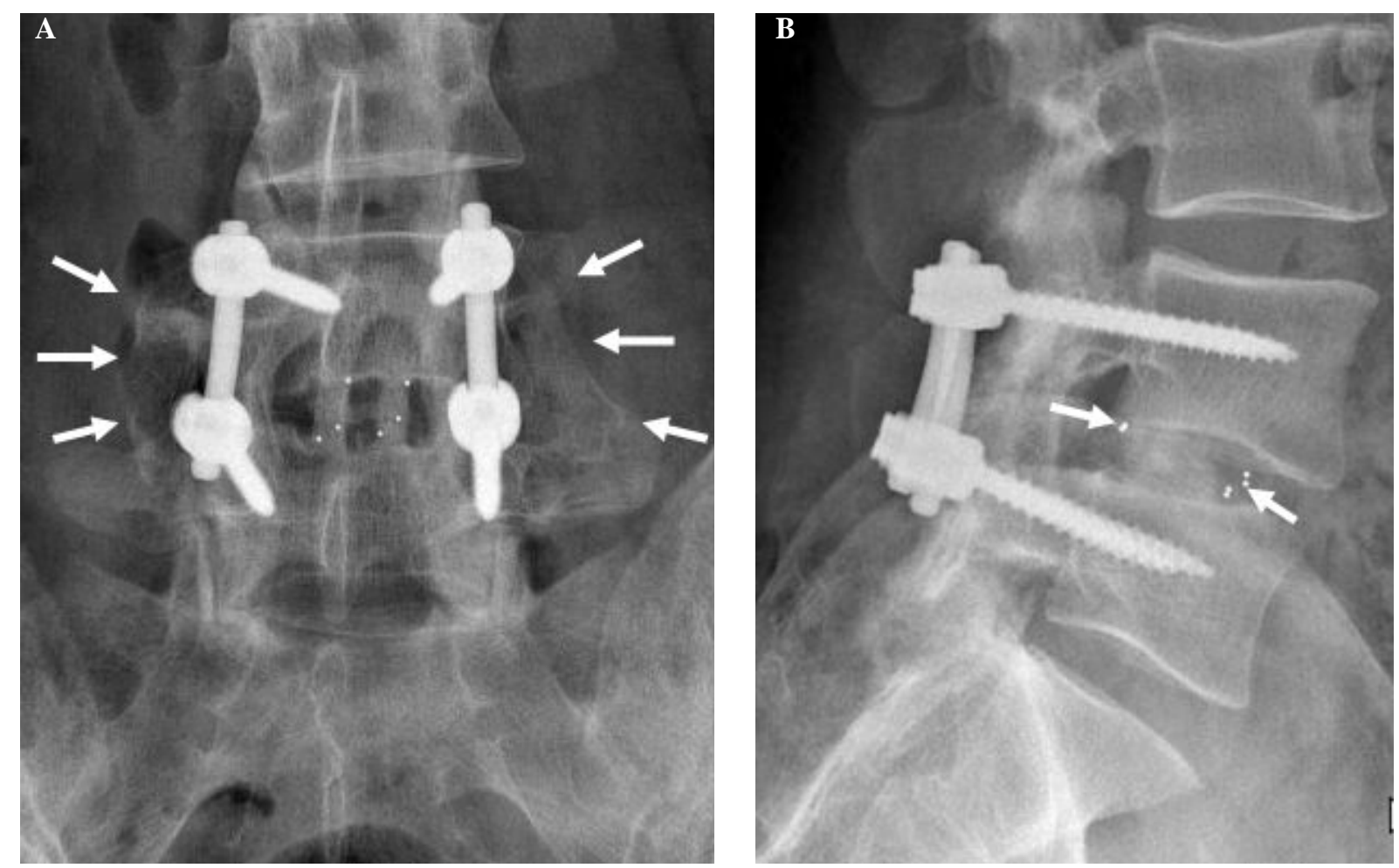

Fig. 1. (A) Antero-posterior (AP) view of the lumbar spine showing a PLIF technique. Arrows show the posterolateral autologous bone graft (B) Lateral view of the same patient. Arrows show the radio-opaque markers embedded in the cages that have been filled with bone graft.

Fritzell et al., 2001; Mirza and Deyo, 2007). Results have varied, with fusion not proving its superiority as compared to placebo or non-operative treatment (Gibson et al., 1999). A multi-centred randomised trial performed in Sweden nevertheless, provided evidence that surgery may be more effective than non-surgical treatment in patients suffering with low back pain secondary to degenerative disc disease (Fritzell et al., 2001). A study by a Norwegian team however, failed to show the superiority of surgery if conservative treatment was carried out using a more intensive approach including cognitive intervention (Brox et al., 2003). Furthermore, long-term consequences such as adjacent segment disease have also increased concerns for the use of spinal fusion (Gillet, 2003; Okuda et al., 2004; Park et al., 2004; Levin et al., 2007; Harrop et al., 2008). Several changes have been observed such as dehydration, disc space narrowing, osteophyte formation and progressive deformity at levels adjacent to a fused spinal segment (Gillet, 2003). Given the debatable efficacy of spinal fusion and its possible implication in the degeneration of the adjacent segments, various non-fusion techniques have been developed.

\section{Artificial/total disc replacement}

Total disc replacement (TDR) technology is not totally new. Attempts have been made since the 50 s to produce an implant that can mimic, to some extent, the function of the

Fig. 2. Lateral view of ALIF procedure at the L5-S1 level.

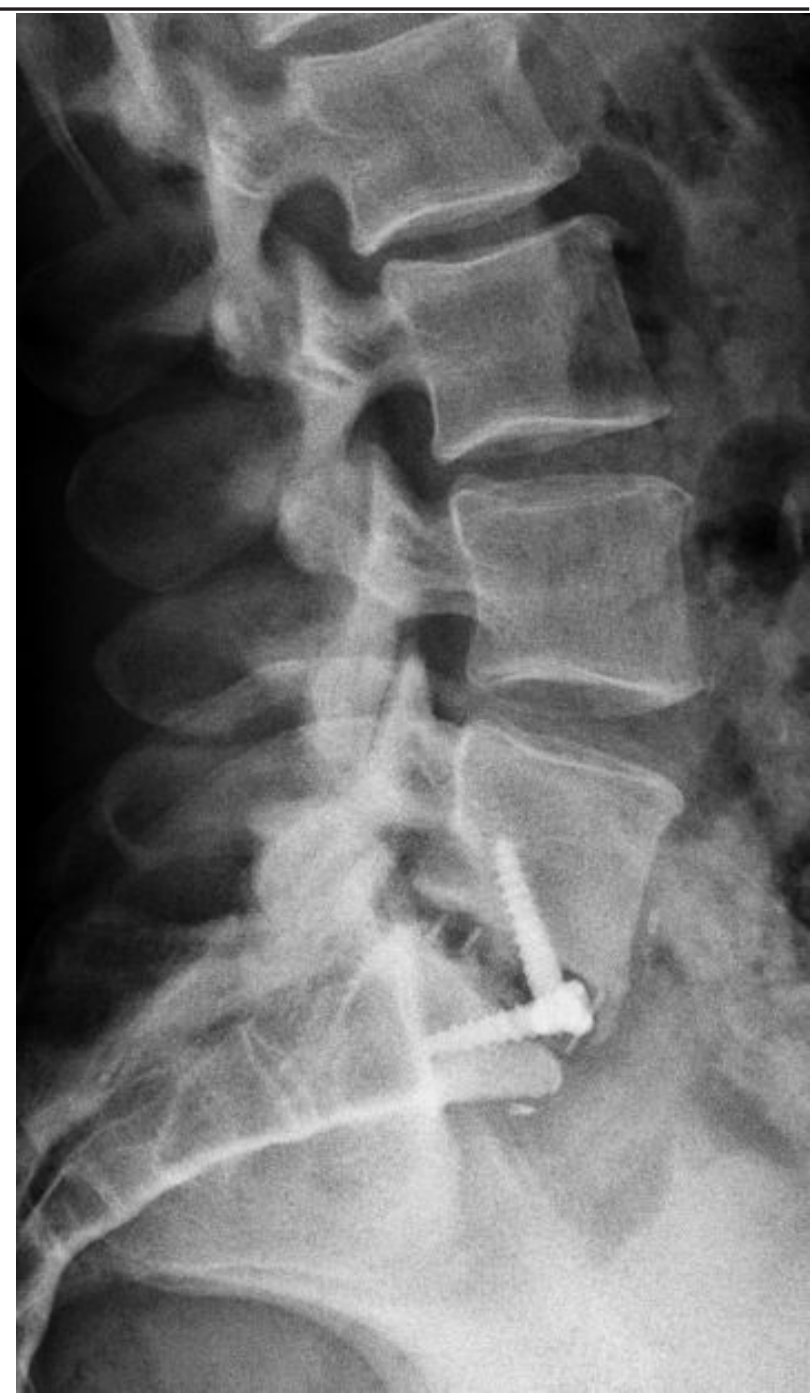


normal IVD. More widespread application followed after the mid 80s developments of a TDR designed at the Charite Hospital in Berlin, Germany (Fig. 3). In theory, a TDR aims to restore the physiological kinematics of the IVD, resist wear, and relieve pain, while avoiding instability and protecting the adjacent discs and facet joints from undue degeneration. The surgical approach is similar to the one used to obtain an anterior lumbar interbody fusion and carries similar rates of vascular complications. The principle of replacing almost the entire IVD is based on the analogous success of hip and knee replacements. As such, materials that have been used for TDR are similar to those that have been employed in other major joint arthroplasties for many years (e.g., polyethylene, chrome cobalt, titanium). Some TDR designs are unconstrained (Charite) while others are semi-constrained (Maverick, Prodisc) or even constrained (FlexiCore).

Similar to spinal fusion, some of the indications for total disc replacement include failure of aggressive conservative treatment with disabling low back pain attributed to degenerative disc disease of the lower lumbar spine affecting no more than two discs. In TDR, since the IVD is replaced, it must be thought that this is the source of back pain (Fekete and Porchet, 2010). Thus, intact facet joints posteriorly are thought to be a prerequisite (Fekete and Porchet, 2010; Kishen and Diwan, 2010). Contraindications to TDR include: lumbar spinal stenosis, old fractures, instability as seen in spondylolisthesis, osteoporosis and infection. Technically, contraindications for TDR may include patients with a steep lumbosacral angle at the intended TDR level (Fraser, 2004), and patients with less than $4 \mathrm{~mm}$ of retained IVD space (Bertagnoli and Kumar, 2002; Resnick and Watters, 2007).

Several reviews of the published literature and clinical trials have been performed to investigate the efficacy and safety of TDR (Delamarter et al., 2003; Zigler, 2003; Blumenthal et al., 2005; Freeman and Davenport, 2006; Harrop et al., 2008; Heller et al., 2009; Resnick and Watters, 2007; Zigler et al., 2007; Fekete and Porchet, 2010). A randomised controlled trial (RCT) comparing lumbar TDR using the Charite with spinal fusion demonstrated TDR clinical outcomes to be equivalent to those with anterior lumbar interbody fusion (Blumenthal et al., 2005). In another RCT, the authors conclude that TDR is safe and efficacious, and that Prodisc-L is superior to circumferential fusion by multiple clinical criteria (Zigler et al., 2007). Others report that TDR as compared to spinal fusion is superior to the latter technique six months following surgery (Zigler, 2003), but at twelve months the difference appeared to be less pronounced (Delamarter et al., 2003). Interestingly a retrospective study on the Charite disc, including some earlier designs of the implant, showed that at seventeen years the majority of operated levels lost mobility and resulted in ankylosis (Putzier et al., 2006). This finding is amplified in systematic reviews, cautioning readers that the long-term complications and benefits of TDR are yet to be realised, especially in terms of preventing adjacent level disc degeneration (Freeman and Davenport, 2006; Resnick and Watters, 2007).

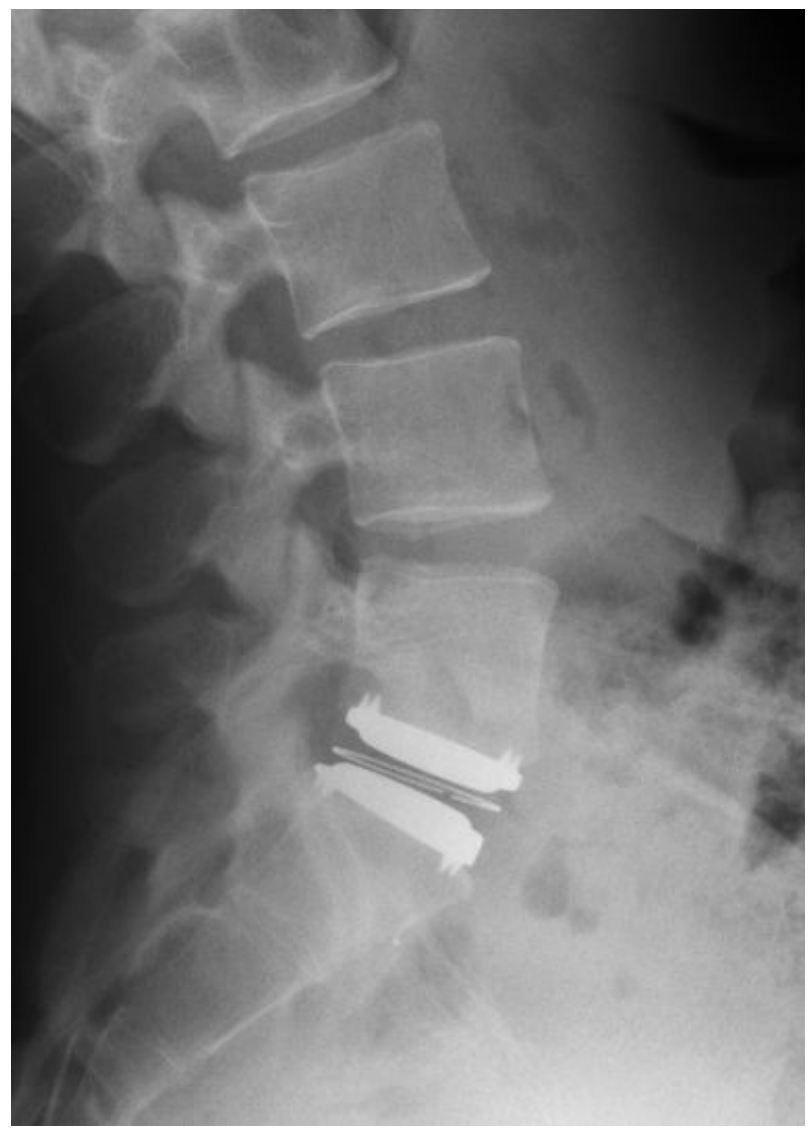

Fig. 3. Lateral view of a TDR (Charite type) implanted at the L5-S1 level.

\section{Nucleus replacement}

Nucleus replacement arthroplasty aims to replace the IVD nucleus while preserving the annulus and vertebral endplates (Bao and Yuan, 2002; Ahrens et al., 2009). Adding to the appeal is that this may be performed in a minimally invasive manner (Fraser, 2004). However, even with a minimally invasive approach, a passage through the annulus for the prosthesis must be made or a lesion must already exist. Furthermore, this technique does not address degenerative changes that may already be present in the outer annulus and/or the vertebral endplates. Two different indications for nucleus replacement have to be considered. That is: (a) replacement of the nucleus following microdiscectomy surgery; or (b) for the treatment of degenerative disc disease.

Historically, various materials have been tried in order to replace the nucleus of the IVD. These include: polymethylmethacrylate (PMMA), polyvinyl alcohol/ polyvinyl pyrollidine copolymer, polycarbonate urethane, albumin, silicon, and stainless steel (Bao and Yuan, 2002; Bao et al., 2002; Klara and Ray, 2002; Allen et al., 2004; Bertagnoli et al., 2005a; Bertagnoli et al., 2005b; Coric and Mummaneni, 2008). Newer materials and designs are constantly being developed to dynamically stabilise the spinal motion segment, preserve disc height, and reestablish load-sharing with the annulus (Goins et al., 2005; 
Ahrens et al., 2009;). Different designs present different challenges but, in general, nuclear replacement designs must resist migration, avoid subsidence, as well as manage the risk of device expulsion.

The available devices can be classified into mechanical or elastomeric nuclei. The latter can be either made of a hydrogel or a non-hydrogel substance, and are available in injectable or pre-formed shapes (Coric and Mummaneni, 2008). The more widely used replacement has been the prosthetic disc nucleus (PDN) developed by Ray (Ray, 2002; Fraser, 2004). The PDN consists of a predefined geometry core enclosed in a polyethylene cover. Nevertheless, this nuclear replacement has not been primarily used for low back pain, but as an adjunct to disc surgery following removal of the nucleus in cases of disc herniation. So far, several thousands of these implants have been used in clinical practice and although initially there were concerns of dislodgement, modification to the design has improved safety. Currently, there are no RCT comparing nuclear replacements with other degenerative disc disease treatment options. With the addition of short and long-term RCT and design improvement to address the aforementioned concerns for example, nucleus replacement arthroplasty may gain in popularity.

\section{Dynamic stabilisation}

With a view to address some of the shortfalls of spinal fusion, alternative options for the last decade have included the use of semi-rigid or dynamic stabilisation implants. Semi-rigid stabilisation aims to achieve fusion without stress shielding at the bone graft that may disrupt or delay bridging. Here, we focus on dynamic stabilisation, which aims to stabilise while restricting painful motion without the need for discectomy and fusion (Mulholland and Sengupta, 2002; Sengupta, 2004; Christie et al., 2005).

The devices most studied are the Graf (Hadlow et al., 1976; Mulholland and Sengupta, 2002; Huang et al., 2005) and the Dynesys (Mulholland and Sengupta, 2002; Stoll et al., 2002). The Graf consists a non-elastic band sometimes referred to as a prosthetic ligament that is attached between pedicles screws, placing the motion segment to be stabilised in lordosis (Mulholland and Sengupta, 2002; Huang et al., 2005). The idea behind this concept was that the device would limit flexion to within the normal range. Although the Graf device showed significant clinical success (Grevitt et al., 1995; Mulholland and Sengupta, 2002), when compared to more conventional treatments, it was associated with worse clinical outcomes at one year and higher revisions with poor outcome after two years (Hadlow et al., 1998). The design of the Dynesys is similar to the Graf with the exception that it has an additional polycarbonate-urethane spacer around the polyethylene terephthalate band between the pedicle screws (Schwarzenbach et al., 2005; Kelly et al., 2010) (Fig. 4). Thus, in addition to the band limiting flexion, the added spacer limits extension (Schulte et al., 2008; Kelly et al., 2010). The goals of the Dynesys are to

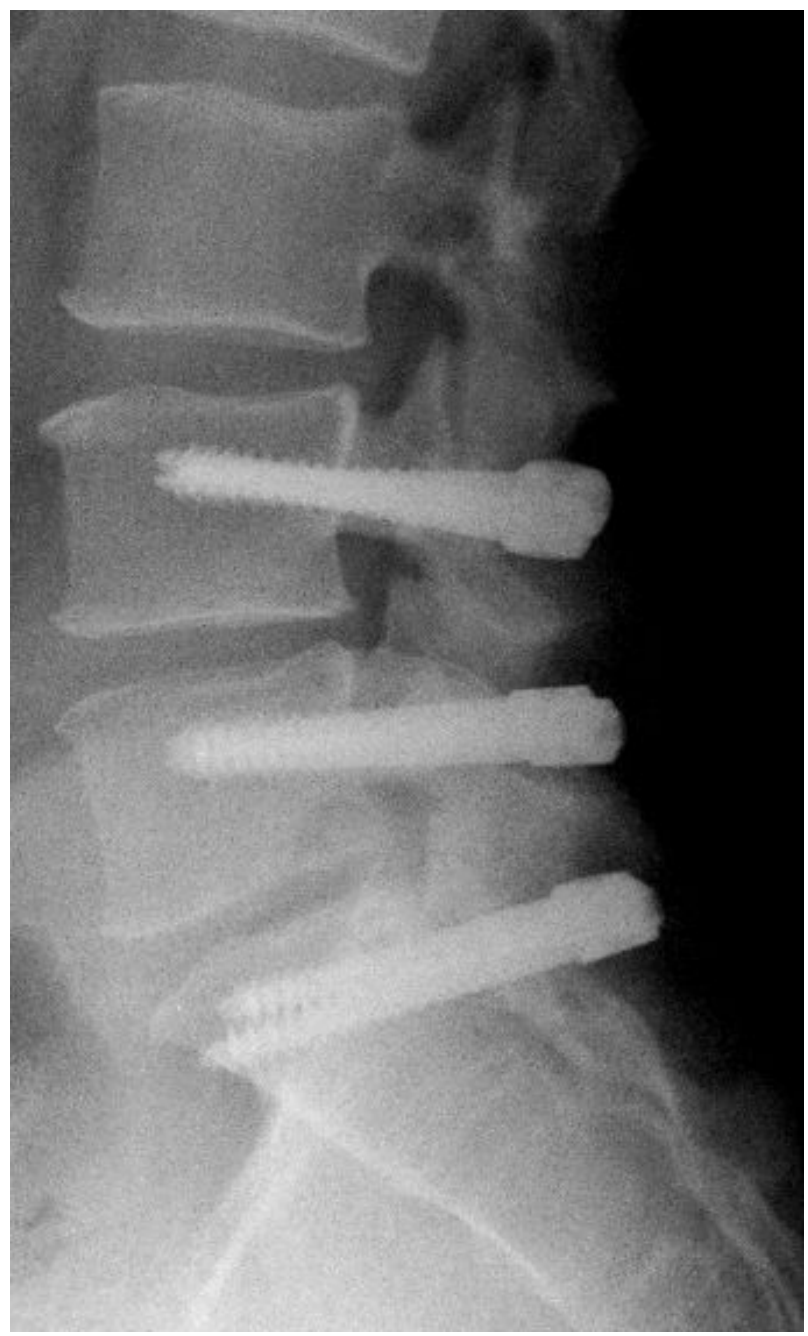

Fig. 4. Lateral view of the lumbar spine of a patient who underwent two-level (L4-S1) dynamic stabilisation (DYNESYS implants).

restore the biomechanics of the posterior annulus and facet joints (Schwarzenbach et al., 2005). Indications for the Dynesys are low back pain due to early disc degeneration, but it has also been applied to stabilise degenerative spondylolisthesis or scoliosis following decompression (Schaeren et al., 2008). In terms of clinical outcomes, results from the literature are mixed. Results from Beastall and colleagues confirm that the Dynesys allows movement of the instrumented level without significant increases in motion at the adjacent levels (Beastall et al., 2007). In contrast, results from a more recent study by Cakir and colleagues showed no effect between the Dynesys and fusion with regards to increased motion at the adjacent segments (Cakir et al., 2009; Kelly et al., 2010). Furthermore, a study based on patient-outcomes found no support for the use of the Dynesys as compared to fusion (Grob et al., 2005). The same study also found relatively high reoperation rates after use of the Dynesys device. To date there are no prospective RCT comparing this type of technology to more conventional treatments (e.g., spinal fusion) for the treatment of degenerative disc disease. Such studies may help clarify the efficacy of dynamic stabilisation. 
Unlike the aforementioned Graf and Dynesys that are fixed to the vertebrae by the use of pedicle screws, interspinous implants are floating devices with the advantage of limiting the possibility of loosening during motion (Sengupta, 2004). Similar to dynamic stabilisation devices and classified as such, their basic design aims to avoid excessive extension and unload the posterior annulus, which is regarded as the primary pain source. Different designs however serve different indications, some limiting flexion and/or extension.

Interspinous devices consist of either compressible or non-compressible implants (Fig. 5). They are usually introduced through a minimal invasive approach between the spinous processes of the affected level. This technology again has not been studied in a prospective randomised way, at least as far as treating discogenic low back pain is concerned. Nevertheless, there have been studies evaluating the efficacy of such devices in a different setting, namely that of spinal stenosis, in which there appears to be some effectiveness, albeit limited in time (Zucherman et al., 2005).

\section{Intradiscal electrothermal therapy}

Intradiscal electrothermal therapy (IDET) is a relatively new percutaneous technique, initially reported by Saal et al., for the treatment of discogenic low back pain (Saal and Saal, 2000). It involves inserting a navigable electrothermal catheter to the inner posterior annulus and delivering heat that aims at inducing retraction of the annular collagen, therefore coagulating inflammatory tissue and nerve endings in the periphery of the disc posteriorly (Saal and Saal, 2000). Although somewhat difficult to achieve, placement of the electrothermal catheter should aim to allow for the active portion of the catheter to provide sufficient heat to spread to both the outer and inner annulus (Karasek and Bogduk, 2000; Derby et al., 2008).

Examples of indications for IDET include severe chronic low back pain for greater than 3 months, persistent pain after at least 3 months of aggressive conservative treatment, normal neurological examination, less than 30\% collapse of the disc space, and no measureable segmental instability (e.g., spondylolisthesis) (Saal and Saal, 2004).

Even though initial results from Saal et al. were encouraging, recent systematic reviews concluded that there was not enough evidence available to support its efficacy or effectiveness for the treatment of discogenic low back pain (Urrutia et al., 2007; Freeman and Mehdian, 2008). RCTs comparing IDET as a treatment of discogenic low back pain with placebo have reported conflicting results. One study noted no statistically or clinically significant differences between IDET and placebo (Freeman et al., 2005), while another concluded that IDET is an effective treatment (Pauza et al., 2004). These differences may in part be explained by differences in patient inclusion criteria and severity of disease, and outcomes used to measure success.

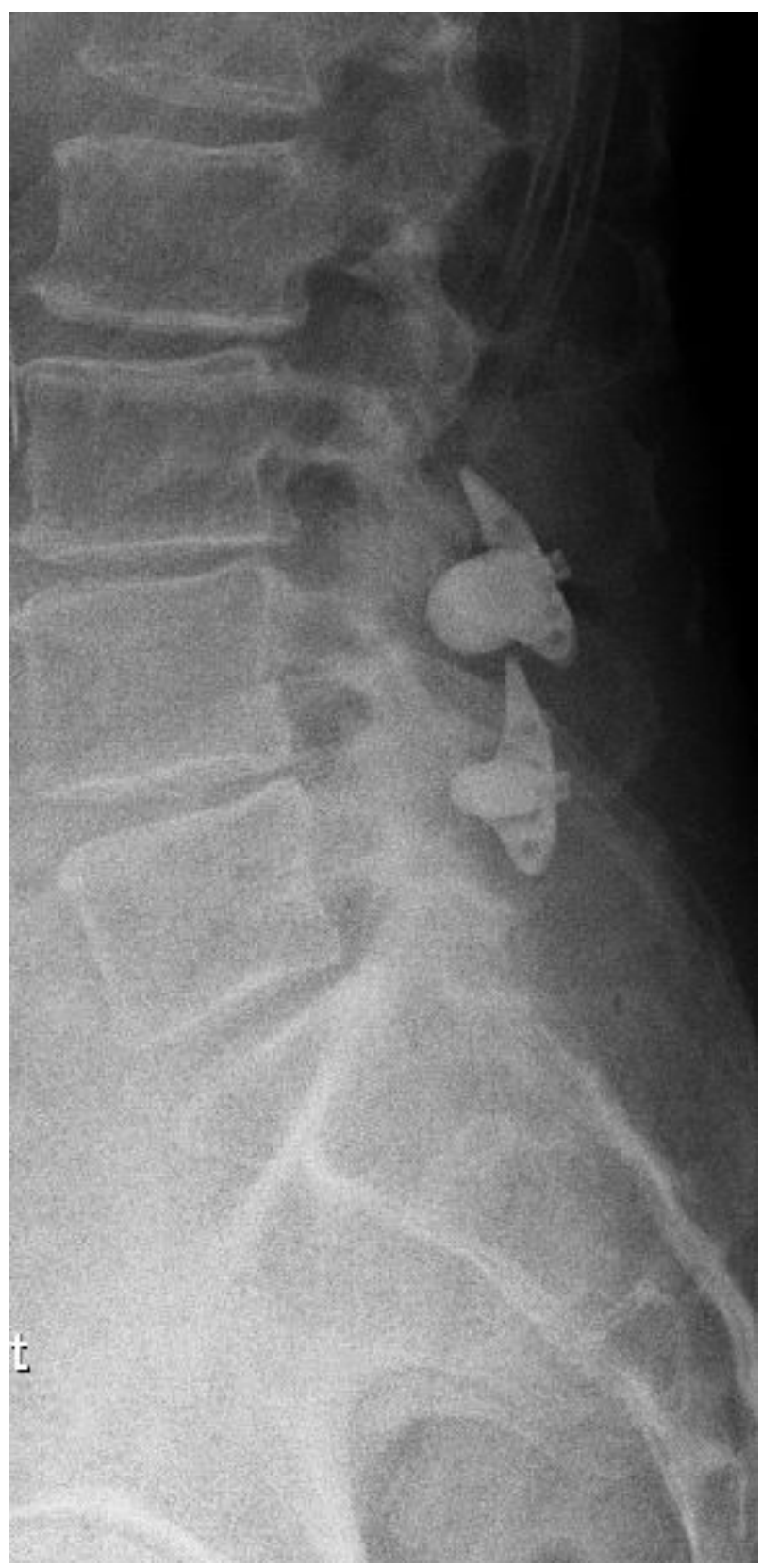

Fig. 5. Lateral view of the lumbar spine showing two non-compressible interspinous devices implanted at the L3-4 and L4-5 levels.

\section{Authors' preferred treatment}

In clinical practice, the senior author bases treatment decisions on clinical experience and evidence based studies from the literature whenever possible. All patients with low back pain are treated by a multidisciplinary team. Patients are offered a comprehensive rehabilitation program including some type of cognitive intervention. Patients who fail to respond to this conservative approach will be considered for surgery, providing that disc degeneration confirmed on MRI is limited to one or two levels. In non-obese patients, an anterior approach is offered favouring fusion (ALIF) at the less mobile L5-S1 level, and total disc arthroplasty at the L4-5 level, 
combining those two approaches for a two level involvement. For the remaining cases, a posterior approach is carried out using a PLIF technique. Given the lack of long term results in the context of painful disc degeneration, nucleus replacement and dynamic stabilisation are not part of the routinely carried out procedures. Interspinous devices are only employed in selected spinal stenosis cases but due to the lack of evidence based studies are not used for discogenic back pain. Finally, IDET is not reimbursed by the Swiss health care system and is therefore not available as a treatment option.

\section{Conclusion}

Low back pain is a multi-factorial problem affecting a great majority of the adult population. Thus, treatment of low back pain resistant to conservative management is still a very complex issue. The currently available surgical options are moderately effective with the majority of them having no proven track record. It is therefore not surprising that surgeons are looking towards more physiological solutions, and this is where translational multidisciplinary collaboration between clinicians and researchers may offer great benefit. Current research in biological solutions focusing on either protein injections (e.g., Rh BMP) aiming at up-regulating matrix production, gene transfer, cell therapy or tissue engineering attracts major interest. We are nevertheless, for the time being, well behind routine clinical application of the abovementioned technologies.

In summary, currently only fusion and disc arthroplasty have a track record that allows them to be recommended to patients suffering with low back pain. Newer techniques such as nucleus replacement and interspinous devices require further investigation. Surgeon and patient expectations now rest on new biological developments and close collaboration between clinicians and basic scientists aiming to enhance patient care.

\section{References}

Acaroglu ER, Iatridis JC, Setton LA, Foster RJ, Mow VC, Weidenbaum M (1995) Degeneration and aging affect the tensile behavior of human lumbar anulus fibrosus. Spine 20: 2690-2701.

Ahrens M, Tsantrizos A, Donkersloot P, Martens F, Lauweryns P, Le Huec JC, Moszko S, Fekete Z, Sherman J, Yuan HA, Halm H (2009) Nucleus replacement with the DASCOR disc arthroplasty device: interim two-year efficacy and safety results from two prospective, nonrandomized multicenter European studies. Spine 34: 13761384.

Albee FH (1911) Transplantation of a portion of the tibia into the spine for Pott's disease. J Amer Med Ass 57: 885-886.

Allen MJ, Schoonmaker JE, Bauer TW, Williams PF, Higham PA, Yuan HA (2004) Preclinical evaluation of a poly (vinyl alcohol) hydrogel implant as a replacement for the nucleus pulposus. Spine 29: 515-523.
Andersson GB (1999) Epidemiological features of chronic low-back pain. Lancet 354: 581-585.

Andersson GB, Shen FH (2004) Operative management of the degenerative disc: posterior and posterolateral procedures. In: The Lumbar Spine (Herkowitz HN, Dvorak J, Bell G, Nordin M, Grob D, eds), $3^{\text {rd }}$ edn, Lippincott Williams \& Wilkins, Philadelphia, pp 317-323.

Baker JK, Reardon PR, Reardon MJ, Heggeness MH (1993) Vascular injury in anterior lumbar surgery. Spine 18: 2227-2230.

Bao QB, Yuan HA (2002) New technologies in spine: nucleus replacement. Spine 27: 1245-1247.

Bao QB, Yuan HA, Bao QB, Yuan HA (2002) Prosthetic disc replacement: the future? Clin Orthop Rel Res 394: 139-145.

Beastall J, Karadimas E, Siddiqui M, Nicol M, Hughes J, Smith F, Wardlaw D (2007) The Dynesys lumbar spinal stabilization system: a preliminary report on positional magnetic resonance imaging findings. Spine 32: 685-690.

Bertagnoli R, Kumar S (2002) Indications for full prosthetic disc arthroplasty: a correlation of clinical outcome against a variety of indications. Eur Spine J 11 Suppl 2: S131-S136.

Bertagnoli R, Karg A, Voigt S (2005a) Lumbar partial disc replacement. Orthop Clin North Am 36: 341-347.

Bertagnoli R, Sabatino CT, Edwards JT, Gontarz GA, Prewett A, Parsons JR (2005b) Mechanical testing of a novel hydrogel nucleus replacement implant. Spine J 5: 672-681.

Blumenthal S, McAfee PC, Guyer RD, Hochschuler SH, Geisler FH, Holt RT, Garcia R Jr, Regan JJ, Ohnmeiss DD (2005) A prospective, randomized, multicenter Food and Drug Administration investigational device exemptions study of lumbar total disc replacement with the CHARITE artificial disc versus lumbar fusion: Part I: Evaluation of clinical outcomes. Spine 30: 1565-1575.

Boden SD, Davis DO, Dina TS, Patronas NJ, Wiesel SW (1990) Abnormal magnetic-resonance scans of the lumbar spine in asymptomatic subjects. A prospective investigation. J Bone Joint Surg Am 72: 403-408.

Bono CM, Lee CK (2004) Critical analysis of trends in fusion for degenerative disc disease over the past 20 years: influence of technique on fusion rate and clinical outcome. Spine 29: 455-463.

Brox JI, Sorensen R, Friis A, Nygaard O, Indahl A, Keller A, Ingebrigtsen T, Eriksen HR, Holm I, Koller AK, Riise R, Reikeras O (2003) Randomized clinical trial of lumbar instrumented fusion and cognitive intervention and exercises in patients with chronic low back pain and disc degeneration. Spine 28: 1913-1921.

Butler D, Trafimow JH, Andersson GB, McNeill TW, Huckman MS (1976) Discs degenerate before facets. Spine 15: 111-113.

Cakir B, Carazzo C, Schmidt R, Mattes T, Reichel H, Kafer W (2009) Adjacent segment mobility after rigid and semirigid instrumentation of the lumbar spine. Spine 34: 1287-1291.

Cassinelli EH, Hall RA, Kang JD (2001) Biochemistry of intervertebral disc degeneration and the potential for gene therapy applications. Spine J 1: 205-214. 
Cheung KM, Chan D, Karppinen J, Chen Y, Jim JJ, Yip SP, Ott J, Wong KK, Sham P, Luk KD, Cheah KS, Leong JC, Song YQ (2006) Association of the Taq I allele in vitamin $\mathrm{D}$ receptor with degenerative disc disease and disc bulge in a Chinese population. Spine 31: 1143-1148.

Christie SD, Song JK, Fessler RG (2005) Dynamic interspinous process technology. Spine 30: S73-S78.

Cloward RB (1953) The treatment of ruptured lumbar intervertebral discs by vertebral body fusion. I. Indications, operative technique, after care. J Neurosurg10: 154-168.

Coric D, Mummaneni PV (2008) Nucleus replacement technologies. J Neurosurg Spine 8: 115-120.

Delamarter RB, Fribourg DM, Kanim LE, Bae H (2003) ProDisc artificial total lumbar disc replacement: introduction and early results from the United States clinical trial. Spine 28: S167-S175.

Derby R, Baker RM, Lee CH, Anderson PA (2008) Evidence-informed management of chronic low back pain with intradiscal electrothermal therapy. Spine J 8: 80-95.

Deyo RA, Weinstein JN (2001) Low back pain. N Engl J Med 344: 363-370.

Eyre DR (1979) Biochemistry of the intervertebral disc. Intl Rev Conn Tiss Res 8: 227-291.

Fekete TF, Porchet F (2010) Overview of disc arthroplasty-past, present and future. Acta Neurochir (Wien) 152: 393-404.

Ferguson SJ, Steffen T (2003) Biomechanics of the aging spine. Eur Spine J 12 Suppl 2: S97-S103.

Fraser RD (2004) Lumbar disc replacement: current model, results, and the future. In: The Lumbar Spine (Herkowitz HN, Dvorak J, Bell G, Nordin M, Grob D, eds), 3rd edn. Lippincott Williams \& Wilkins, Philadelphia, pp 393-398.

Freeman BJ, Davenport J (2006) Total disc replacement in the lumbar spine: a systematic review of the literature. Eur Spine J 15 Suppl 3: S439-S447.

Freeman BJ, Mehdian R (2008) Intradiscal electrothermal therapy, percutaneous discectomy, and nucleoplasty: what is the current evidence? Curr Pain Headache Rep 12: 14-21.

Freeman BJ, Fraser RD, Cain CM, Hall DJ, Chapple DC (2005) A randomized, double-blind, controlled trial: intradiscal electrothermal therapy versus placebo for the treatment of chronic discogenic low back pain. Spine 30: 2369-2377.

Fritzell P, Hagg O, Wessberg P, Nordwall A, Swedish Lumbar Spine Study Group. (2001) 2001 Volvo Award Winner in Clinical Studies: Lumbar fusion versus nonsurgical treatment for chronic low back pain: a multicenter randomized controlled trial from the Swedish Lumbar Spine Study Group. Spine 26: 2521-2532.

Gibson JN, Waddell G (2005) Surgery for degenerative lumbar spondylosis: updated Cochrane Review. Spine 30: 2312-2320.

Gibson JN, Grant IC, Waddell G (1999) The Cochrane review of surgery for lumbar disc prolapse and degenerative lumbar spondylosis. Spine 24: 1820-1832.

Gillet P (2003) The fate of the adjacent motion segments after lumbar fusion. J Spinal Disord Tech 16: 338-345.
Goins ML, Wimberley DW, Yuan PS, Fitzhenry LN, Vaccaro AR (2005) Nucleus pulposus replacement: an emerging technology. Spine J 5: 317S-324S.

Grevitt MP, Gardner AD, Spilsbury J, Shackleford IM, Baskerville R, Pursell LM, Hassaan A, Mulholland RC (1995) The Graf stabilisation system: early results in 50 patients. Eur Spine J 4: 169-175.

Grob D, Benini A, Junge A, Mannion AF (2005) Clinical experience with the Dynesys semirigid fixation system for the lumbar spine: surgical and patient-oriented outcome in 50 cases after an average of 2 years. Spine 30: 324-331.

Grubb SA, Lipscomb HJ (1992) Results of lumbosacral fusion for degenerative disc disease with and without instrumentation. Two- to five-year follow-up. Spine 17: 349-355.

Hadjipavlou AG, Simmons JW, Pope MH, Necessary JT, Goel VK (1999) Pathomechanics and clinical relevance of disc degeneration and annular tear: a point-of-view review. Am J Orthop 28: 561-571.

Hadjipavlou AG, Tzermiadianos MN, Bogduk N, Zindrick MR (2008) The pathophysiology of disc degeneration: a critical review. J Bone Joint Surg $\mathrm{Br}$ 90: 1261-1270.

Hadlow SV, Fagan AB, Hillier TM, Fraser RD (1998) The Graf ligamentoplasty procedure. Comparison with posterolateral fusion in the management of low back pain. Spine 23: 1172-1179.

Hanley EN Jr, David SM (1999) Lumbar arthrodesis for the treatment of back pain. J Bone Joint Surg Am 81: 716-730.

Hannani K, Delamarter R (2004) Operative treatment of anterior procedures. In: The Lumbar Spine (Herkowitz HN, Dvorak J, Bell G, Nordin M, Grob D, eds), 3rd edn. Lippincott Williams \& Wilkins, Philadelphia, pp 331-337.

Harms J, Rolinger H (1982) [A one-stage procedure in operative treatment of spondylolistheses: dorsal tractionreposition and anterior fusion] Zeitschr Orthopadie und Ihre Grenzgeb 120: 343-347.

Harrop JS, Youssef JA, Maltenfort M, Vorwald P, Jabbour P, Bono CM, Goldfarb N, Vaccaro AR, Hilibrand AS (2008) Lumbar adjacent segment degeneration and disease after arthrodesis and total disc arthroplasty. Spine 33: 1701-1707.

Hart LG, Deyo RA, Cherkin DC (1995) Physician office visits for low back pain. Frequency, clinical evaluation, and treatment patterns from a U.S. national survey. Spine 20: 11-19.

Heller JG, Sasso RC, Papadopoulos SM, Anderson PA, Fessler RG, Hacker RJ, Coric D, Cauthen JC, Riew DK (2009) Comparison of BRYAN cervical disc arthroplasty with anterior cervical decompression and fusion: clinical and radiographic results of a randomized, controlled, clinical trial. Spine 34: 101-107.

Hibbs RA (1911) An operation for progressive spinal deformities. NY Med J 93: 1013-1016.

Huang RC, Wright TM, Panjabi MM, Lipman JD (2005) Biomechanics of nonfusion implants. Orthop Clin North Am 36: 271-280. 
Jeanneret B, Jovanovic M, Magerl F (1994) Percutaneous diagnostic stabilization for low back pain. Correlation with results after fusion operations. Clin Orthop Relat Res 304: 130-138.

Karasek M, Bogduk N (2000) Twelve-month followup of a controlled trial of intradiscal thermal anuloplasty for back pain due to internal disc disruption. Spine 25: 2601-2607.

Kawaguchi Y, Kanamori M, Ishihara H, Ohmori K, Matsui H, Kimura T (2002) The association of lumbar disc disease with vitamin-D receptor gene polymorphism. J Bone Joint Surg Am Vol 84A: 2022-2028.

Kelly MP, Mok JM, Berven S (2010) Dynamic constructs for spinal fusion: an evidence-based review. Orthop Clin North Am 41: 203-215.

Kishen TJ, Diwan AD (2010) Fusion versus disk replacement for degenerative conditions of the lumbar and cervical spine: quid est testimonium? Orthop Clin North Am 41: 167-181.

Klara PM, Ray CD (2002) Artificial nucleus replacement: clinical experience. Spine 27: 1374-1377.

Krishna M, Pollock RD, Bhatia C (2008) Incidence, etiology, classification, and management of neuralgia after posterior lumbar interbody fusion surgery in 226 patients. Spine J 8: 374-379.

Levin DA, Hale JJ, Bendo JA (2007) Adjacent segment degeneration following spinal fusion for degenerative disc disease. Bull NYU Hosp Jt Dis 65: 29-36.

Martin MD, Boxell CM, Malone DG (2002) Pathophysiology of lumbar disc degeneration: a review of the literature. Neurosurg Focus 13: E1.

Miller JA, Schmatz C, Schultz AB (1976) Lumbar disc degeneration: correlation with age, sex, and spine level in 600 autopsy specimens. Spine 13: 173-178.

Mirza SK, Deyo RA (2007) Systematic review of randomized trials comparing lumbar fusion surgery to nonoperative care for treatment of chronic back pain. Spine 32: 816-823.

Mulholland RC, Sengupta DK (2002) Rationale, principles and experimental evaluation of the concept of soft stabilization. Eur Spine J 11 Suppl 2: S198-S205.

Ohshima H, Urban JP, Bergel DH (1995) Effect of static load on matrix synthesis rates in the intervertebral disc measured in vitro by a new perfusion technique. J Orthop Res 13: 22-29.

Okuda S, Iwasaki M, Miyauchi A, Aono H, Morita M, Yamamoto T (2004) Risk factors for adjacent segment degeneration after PLIF. Spine 29: 1535-1540.

Park P, Garton HJ, Gala VC, Hoff JT, McGillicuddy JE (2004) Adjacent segment disease after lumbar or lumbosacral fusion: review of the literature. Spine 29: 1938-1944.

Pauza KJ, Howell S, Dreyfuss P, Peloza JH, Dawson K, Bogduk N (2004) A randomized, placebo-controlled trial of intradiscal electrothermal therapy for the treatment of discogenic low back pain. Spine J 4: 27-35.

Putzier M, Funk JF, Schneider SV, Gross C, Tohtz SW, Khodadadyan-Klostermann C, Perka C, Kandziora F (2006) Charite total disc replacement - clinical and radiographical results after an average follow-up of 17 years. Eur Spine J 15: 183-195.
Ray CD (2002) The PDN prosthetic disc-nucleus device. Eur Spine J 11: S137-S142.

Resnick DK, Watters WC (2007) Lumbar disc arthroplasty: a critical review. Clin Neurosurg 54: 83-87.

Saal JA, Saal JS (2004) Intradiscal electrothermal therapy. In: The Lumbar Spine (Herkowitz HN, Dvorak J, Bell G, Nordin M, Grob D, eds), 3rd edn, Lippincott Williams \& Wilkins, Philadelphia, pp 312-316.

Saal JS, Saal JA (2000) Management of chronic discogenic low back pain with a thermal intradiscal catheter. A preliminary report. Spine 25: 382-388.

Schaeren S, Broger I, Jeanneret B (2008) Minimum four-year follow-up of spinal stenosis with degenerative spondylolisthesis treated with decompression and dynamic stabilization. Spine 33: E636-E642.

Schizas C, Tzinieris N, Tsiridis E, Kosmopoulos V (2009) Minimally invasive versus open transforaminal lumbar interbody fusion: evaluating initial experience. Int Orthopaed 33: 1683-1688.

Schulte TL, Hurschler C, Haversath M, Liljenqvist U, Bullmann V, Filler TJ, Osada N, Fallenberg EM, Hackenberg L (2008) The effect of dynamic, semi-rigid implants on the range of motion of lumbar motion segments after decompression. Eur Spine J 17: 1057-1065.

Schwarzenbach O, Berlemann U, Stoll TM, Dubois G (2005) Posterior dynamic stabilization systems: DYNESYS. Orthop Clin North Am 36: 363-372.

Sengupta DK (2004) Dynamic stabilization in the treatment of low back pain due to degenerative disorders. In: The Lumbar Spine (Herkowitz H, Dvorak J, Bell G, Nordin M, Grob D, eds), 3rd edn, Lippincott Williams \& Wilkins, Philadelphia, pp 373-383.

Sidhu KS, Herkowitz HN (1997) Spinal instrumentation in the management of degenerative disorders of the lumbar spine. Clin Orthop Rel Res 335: 39-53.

Skaggs DL, Weidenbaum M, Iatridis JC, Ratcliffe A, Mow VC (1994) Regional variation in tensile properties and biochemical composition of the human lumbar annulus fibrosus. Spine 19: 1310-1319.

Soegaard R, Christensen FB (2006) Health economic evaluation in lumbar spinal fusion: a systematic literature review anno 2005. Eur Spine J 15: 1165-1173.

Stoll TM, Dubois G, Schwarzenbach O (2002) The dynamic neutralization system for the spine: a multi-center study of a novel non-fusion system. Eur Spine J 11: S170S178.

Tertti M, Paajanen H, Laato M, Aho H, Komu M, Kormano M (1991) Disc degeneration in magnetic resonance imaging. A comparative biochemical, histologic, and radiologic study in cadaver spines. Spine 16: 629-634.

Tsantrizos A, Andreou A, Aebi M, Steffen T (2000) Biomechanical stability of five stand-alone anterior lumbar interbody fusion constructs. Eur Spine J 9: 14-22.

Urrutia G, Kovacs F, Nishishinya MB, Olabe J (2007) Percutaneous thermocoagulation intradiscal techniques for discogenic low back pain. Spine 32: 1146-1154.

Videman T, Leppavuori J, Kaprio J, Battie MC, Gibbons LE, Peltonen L, Koskenvuo M (1998) Intragenic polymorphisms of the vitamin D receptor gene associated with intervertebral disc degeneration. Spine 23: 2477-2485. 
Wood GW, Boyd RJ, Carothers TA, Mansfield FL, Rechtine GR, Rozen MJ, Sutterlin CE, III (1995) The effect of pedicle screw/plate fixation on lumbar/lumbosacral autogenous bone graft fusions in patients with degenerative disc disease. Spine 20: 819-830.

Zdeblick TA (1993) A prospective, randomized study of lumbar fusion. Preliminary results. Spine 18: 983-991.

Zigler JE (2003) Clinical results with ProDisc: European experience and U.S. investigation device exemption study. Spine 28: S163-S166.

Zigler J, Delamarter R, Spivak JM, Linovitz RJ, Danielson GO, III, Haider TT, Cammisa F, Zuchermann J, Balderston R, Kitchel S, Foley K, Watkins R, Bradford D, Yue J, Yuan H, Herkowitz H, Geiger D, Bendo J, Peppers T, Sachs B, Girardi F, Kropf M, Goldstein J (2007) Results of the prospective, randomized, multicenter Food and Drug Administration investigational device exemption study of the ProDisc-L total disc replacement versus circumferential fusion for the treatment of 1-level degenerative disc disease. Spine 32: 1155-1162.

Zucherman JF, Hsu KY, Hartjen CA, Mehalic TF, Implicito DA, Martin MJ, Johnson DR, Skidmore GA, Vessa PP, Dwyer JW, Puccio ST, Cauthen JC, Ozuna RM (2005) A multicenter, prospective, randomized trial evaluating the $X$ STOP interspinous process decompression system for the treatment of neurogenic intermittent claudication: two-year follow-up results. Spine 30: 1351-1358.

\section{Discussion with Reviewers}

Reviewer I: What role does the age and the activity level of the patient play in the indication for the various surgical treatment options?
Authors: In principle, in younger patients one would tend to favour non fusion techniques. Activity level on the other hand has to be taken into account. In active young athletes, spinal fusion of a single level, in particular of the lesser mobile L5 -S1 disc is the author's preferred treatment. Once bony union has been achieved for example, there would be less issues with material fatigue and wear. More than age, bone quality may actually dictate the treatment options. Spinal arthroplasty would not be considered in patients with osteoporosis and thus spinal fusion would be more appropriate. Obesity could also play a role in deciding what treatment to consider. Anterior surgery would be technically more complex in such patients and thus the senior author would prefer a more conservative posterior technique.

Reviewer II: Discogenic back pain is not necessarily a morphological issue, but a biochemical one. Which treatment options would thus be more promising than surgery? What should basic research predominantly investigate in the future?

Authors: Treatment options will have to be adapted to various degrees of disc degeneration. For moderate cases, with a relatively intact annulus, some type of biological enhancement of the nucleus may be desirable. Unfortunately, the disc is a hostile environment, and unless disc nutrition is enhanced, there is a good chance that this type of biological approach would fail. For more advanced degeneration, including annular degeneration and secondary facet joint changes, a more drastic approach may be needed. Current disc replacements do not replicate physiological motion patterns or load transmission. Further research and development in implant design and materials, along with innovative implantation techniques avoiding the risks of major anterior surgery, may be the way forward. 